\title{
Analisis Nilai Tambah Agroindustri Kopi Bubuk Organik Di Desa Gunung Terang Kecamatan Way Tenong Kabupaten Lampung Barat
}

\author{
Faizal Daud
}

Dosen Universitas Sjakhyakirti

Jln. Sultan Muhammad Mansyur Kb. Gede 32 Ilir, Palembang. 30145. Sumatera Selatan. Indonesia

\begin{abstract}
The objectives of this study were to: 1) calculate the cost, revenue and income of the organic ground coffee agro-industry in Gunung Terang Village, Way Tenong District, West Lampung Regency, 2) calculate the added value obtained from the processing of organic ground coffee agro-industry in Gunung Terang Village, District Way Tenong, West Lampung Regency, 3) to analyze the financial feasibility of the organic ground coffee agro-industry in Gunung Terang Village, Way Tenong District, West Lampung Regency. The results showed that the total production cost of the organic ground coffee agro-industry in Gunung Terang Village, Way Tenong District, West Lampung Regency in one production process was Rp. 3,675,191, the average income was Rp. 4,550,000, the income received was Rp. 879,809. The $R$ / C ratio value is 1.24 indicating that the organic ground coffee agro-industry is profitable. The added value of the organic ground coffee processing agro-industry in Gunung Terang Village, Way Tenong District, West Lampung Regency is IDR 27,459 / Kg. This shows that every sale of $1 \mathrm{~kg}$ of organic ground coffee will provide an added value of Rp. 27,459. The organic ground coffee agro-industry in Gunung Terang Village, Way Tenong District, West Lampung Regency is financially feasible to be developed, this can be seen from the calculation of the NPV value of IDR $631,745,317$, the IRR value is $31.17 \%$ and the Net B value. / C of 3.64 .
\end{abstract}

Key Word : Value-added, Agroindustry, Organic Ground Coffee

\section{PENDAHULUAN}

\section{A. Latar Belakang}

Indonesia merupakan negara kepulauan yang sebagian besar luas wilayahnya merupakan perairan. Ikan merupakan salah satu hasil perikanan yang banyak dihasilkan di Indonesia dan merupakan sumber protein hewani yang banyak dikonsumsi masyarakat. Ikan mudah didapat dengan harga yang relatif murah sehingga dapat dijangkau oleh semua lapisan masyarakat. Kandungan pprotein yang tinggi yaitu $17,00 \%$ dan kadar lemak yaitu $4,50 \%$ yang rendah pada ikan segar sangat bermanfaat bagi kesehatan tubuh manusia. Hasil perikanan bersifat mudah rusak sehingga tingkat kehilangan atau kerusakan pascapanen relatif lebih tinggi dibandingkan dengan bahan pangan lainnya, oleh karena itu, peningkatan produk perikanan harus diimbangi dengan penaganan pascapanen dan teknologi pengolahan yang memadai. Banyak jenis ikan di Indonesia yang belum dimanfaatkan secara optimal. Beberapa jenis ikan tersebut mempunyai prospek yang baik untuk diolah, salah satunya adalah ikan belida (Anonim, 2005).

Perkebunan merupakan salah satu sub setor pertanian yang mempunyai peranan penting dalam meningkatkan pembangunan, diantaranya pemecahan berbagai masalah daerah maupun masalah tenaga kerja, sosial, lingkungan dan lain-lain. Selain itu komoditi perkebunan juga berperan dalam meningkatkan taraf hidup petani, menambah devisa negara dengan menciptakan lapangan pekerjaan dan sekaligus berperan dalam melestariakan sumberdaya alam. Salah satu tanaman perkebunan yang banyak dibudidayakan petani dan perusahaan swasta adalah tanaman kopi. Hal ini disebabkan karena komoditi ini memiliki nilai ekonomi yang tinggi dan strategis, baik untuk memberikan peningkatan pendapatan bahkan dapat menambah devisa negara (Herman, 2013).

Kopi merupakan komoditi penting dalam sub sektor perkebunan, karenaberperan penting dalam perekonomian nasional sebagai sumber devisa negara. Hal ini bisa dilihat dari komoditi ini yang mampu menembus pasar internasional sebagai komoditi ekspor. Ekspor kopi Indonesia menduduki posisi ke 3 di dunia setelah Brazil dan Vietnam dengan volume ekspor 10.627.654 kantung. Hal tersebut dapat dilihat pada tabel 1 berikut :

Tabel 1. Volume Eksport Kopi di Dunia

\begin{tabular}{clc}
\hline No & Negara & Volume Ekspor (Kantung) \\
\hline 1. & Brazil & 28.265 .729 \\
2. & Vietnam & 25.475 .000 \\
3. & Indonesia & $\mathbf{1 0 . 6 2 7 . 6 5 4}$ \\
4. & Columbia & 7.168 .913 \\
\hline
\end{tabular}

Keterangan : 1 kantung setara $60 \mathrm{Kg}$

Sumber : Direktorat Jenderal Perkebunan, 2016.

Indonesia dikenal sebagai negara produsen kopi robusta dengan pangsa sebesar $20 \%$ dari ekspor kopi robusta dunia. Areal kopi robusta tersebar dihampir seluruh kepulauan Indonesia dengan urutan dan persentasi arealsebagai berikut Sumatera (66\%), Jawa (12\%), Bali dan Nusa Tenggara (8\%), Sulawesi (7\%), Kalimantan (4\%), serta Maluku dan Papua (1\%). Sumatera memiliki persentase areal kopi yang besar pada tingkat nasional, dibandingkan dengan pulaupulau yang lain (Ditjen Perkebunan, 2015). Kawasan segitiga kopi Indonesia meliputi provinsi-provinsi di Pulau Sumatera yaitu Lampung, Sumatera Selatan, dan Bengkulu merupakan daerah penghasil kopi robusta 
utama di Indonesia. Hal ini dapat dilihat pada tabel 2 berilut :

Tabel 2. Kontribusi Rata-rata Sentra Produksi Kopi Terhadap Total Produksi Kopi Nasional Beserta Produktivitas di Pulau Sumatera Tahun 2015.

\begin{tabular}{clcc}
\hline No & Provinsi & Produksi (\%) & $\begin{array}{c}\text { Produktifitas } \\
(\mathbf{K g} / \mathbf{H a} / \mathbf{T h})\end{array}$ \\
\hline 1. & Lampung & 26,00 & 1.001 \\
2. & Sumatera Selatan & 21,03 & 652 \\
3. & Bengkulu & 8,49 & 746 \\
4. & Sumatera Utara & 8,38 & 1.022 \\
5. & NAD & 7,26 & 1.156 \\
\hline
\end{tabular}

Sumber : Direktorat Jenderal Perkebunan, 2015.

Jenis kopi yang dibudidayakan ada empat jenis yaitu kopi arabika, kopi Liberika, kopi Canephora (robusta), dan kopi hibrida. Petani di Provinsi Lampung menanam jenis kopi robusta atau Canephora dan kopi arabika, namun mayoritas para petani menanam kopi jenis robusta. Nama robusta digunakan untuk tujuan perdagangan, jenis kopi ini memiliki kelebihan darisegi produksi yang lebih tinggi dibandingkan jenis kopi arabika dan liberika. Kopi robusta bisa ditanam pada ketinggian lahan yang lebih tinggi dari kopi arabika agar dapat tumbuh dan berproduksi dengan baik (Syakir, 2010).

Provinsi Lampung memiliki luas areal tanaman kopi robusta seluas 173.690 hektar yang tersebar luas di seluruh wilayah kabupaten maupun kota. Kabupaten Lampung Barat merupakan salah satu sentra produksi kopi robusta terbesar di Provinsi Lampung, karena memiliki luas areal dan produksi kopi yang cukup tinggi. Hal ini juga karena didukung oleh iklim di Kabupaten Lampung Barat sangat cocok untuk tanaman kopi, sehingga para pengusaha kopi bubuk sangat senang melakukan usaha di daerah tersebut (BPS Propinsi Lampung, 2015).

Tabel 3. Luas Areal Tanaman dan Produksi Kopi Robusta di Provinsi Lampung.

\begin{tabular}{clrcc}
\multicolumn{5}{c}{ Robusta di Provinsi Lampung. } \\
\hline No & Kabupaten & $\begin{array}{c}\text { Luas Areal } \\
\text { (Ha) }\end{array}$ & $\begin{array}{c}\text { Produksi } \\
\text { (Ton) }\end{array}$ & $\begin{array}{c}\text { Produktivitas } \\
\text { (Ton/Ha) }\end{array}$ \\
\hline 1. & Lampung Barat & $\mathbf{6 5 . 0 1 0}$ & $\mathbf{5 2 . 5 4 3}$ & $\mathbf{0 . 8 1}$ \\
2. & Tanggamus & 43.897 & 30.671 & 0.70 \\
3. & Lampung Selatan & 1.239 & 923 & 0.74 \\
4. & Lampung Timur & 966 & 492 & 0.51 \\
5. & Lampung Tengah & 1.549 & 778 & 0.50 \\
6. & Lampung Utara & 18.482 & 12.230 & 0.66 \\
7. & Way Kanan & 22.563 & 17.410 & 0.77 \\
8. & Tulang Bawang & 133 & 63 & 0.47 \\
9. & Pesawaran & 4.649 & 3.542 & 0.76 \\
10. & Pring Sewu & 7.630 & 7.919 & 1.04 \\
11. & Mesuji & 249 & 84 & 0.34 \\
12. & Tulang Bawang Barat & 170 & 35 & 0.21 \\
13. & Pesisir Barat & 6.934 & 4.711 & 0.68 \\
14. & Bandar Lampung & 217 & 99 & 0.46 \\
15. & Kota Metro & 2 & 1 & 0.50 \\
\hline
\end{tabular}

Sumber : BPS. Lampung Dalam Angka. 2015.

Salah satu ciri strategi pembangunan yang harus dimiliki Indonesia yang mempunyai potensi sebagian besar dari sektor pertanian adalah kebijaksanaan pembangunan yang menjaga keterkaitan antara sektor pertanian dengan sector industri dalam bentuk Agroindustri. Agroindustri memiliki peran yang cukup penting yakni meningkatkan kesempatan kerja di pedesaan, nilai tambah, pedapatan bagi petani, dan meningkatkan mutu hasil produksi pertanian yang pada gilirannya dapat memenuhi syarat memasuki pasar luar negeri. Paparan tersebut sesuai dengan program jangka panjang pembangunan ekonomi di Indonesia yaitu mewujudkan struktur ekonomi yang seimbang antara sektor industri dan pertanian (Haryono, 2009).

Salah satu komoditas pertanian yang dapat digunakan sebagai bahan baku agroindustri adalah komoditas perkebunan, contohnya tanaman kopi. Kopi yang dihasilkan dari tanaman perkebunan merupakan komoditas ekspor non migas yang dibutuhkan di berbagai industri minuman. Salah satu produk kopi bubuk yang dihasilkan di Lampung Barat yang dinilai memiliki potensi bisnis yang besar di Indonesia adalah agroindustri kopi bubuk organik. Agroindustri kopi bubuk organik memiliki nilai jual yang sangat tinggi di pasar, terutama di pasar dunia. Kopi bubuk organik seharusnya menjadi alternatif komoditas unggulan agroindustri di masa depan.

Namun kenyataannya hanya sedikit petani yang mau berspekulasi untuk menanam kopi organik. Produsen kopi bubuk yang mau membeli kopi organik sangat sedikit, hal ini menjadi penyebab utama kurangnya minat petani untuk menanam kopi organik karena para petani tidak tahu kepada siapa akan menjual hasil panen kopi organik, selain itu juga sebagian petani beranggapan kopi organik memiliki keuntungan yang relatif rendah.

Kendala dan risiko yang dihadapi dalam memproduksi kopi bubuk organik cukup banyak, namun prospek dan potensi kopi bubuk organik Indonesia cukup cerah di pasar dunia. Hal ini dikarenakan kopi bubuk organik merupakan minuman yang digemari konsumen di seluruh dunia untuk meningkatkan stamina, sehingga permintaan untuk kopi bubuk organik relatif stabil bahkan cenderung mengalami peningkatan. Selain itu, nilai tambah produk kopi bubuk organik yang diperoleh dapat digunakan untuk menutupi semua biaya-biaya yang ada dalam agroindustri kopi bubuk organik.

Hal ini membuat seorang pengusaha di Desa Gunung Terang, Kecamaatan Way Tenong, Kabupaten Lampung Barat berani membangun agroindustri kopi bubuk organik. Pengembangan agroindustri kopi bubuk organik di Desa Gunung Terang Kecamatan Way Tenong Kabupaten Lampung Barat diharapkan dapat meningkatkan nilai tambah komoditas kopi organik. Apabila kopi organik dijual dalam bentuk biji kopi organik kering harganya tidak terlalu tinggi dibandingkan dengan kopi organik dalam bentuk olahan kopi bubuk organik.

\section{B. Rumusan Masalah}

Berdasarkan latar belakang dan uraian di atas, adapun permasalahan yang menarik untuk diteliti adalah sebagai berikut :

1. Berapa besar biaya, penerimaan dan pendapatan agroindustri kopi bubuk organik di Desa Gunung Terang Kecamatan Way Tenong Kabupaten Lampung Barat?

2. Berapa besar nilai tambah yang diperoleh dari pengolahan agroindustri kopi bubuk organik di 
Desa Gunung Terang Kecamatan Way Tenong Kabupaten Lampung Barat?

3. Bagaimana kelayakan financial agroindustri kopi bubuk organik di Desa Gunung Terang Kecamatan Way Tenong Kabupaten Lampung Barat?

\section{Tujuan dan Kegunaan}

Berdasarkan rumusan masalah yang telah dijabarkan, maka secara umum penelitian ini bertujuan untuk :

1. Menghitung besarnya biaya, penerimaan dan pendapatan agroindustri kopi bubuk organik di Desa Gunung Terang Kecamatan Way Tenong Kabupaten Lampung Barat.

2. Menghitung besarnya nilai tambah yang diperoleh dari pengolahan agroindustri kopi bubuk organik di Desa Gunung Terang Kecamatan Way Tenong Kabupaten Lampung Barat.

3. Menganalisis kelayakan financial agroindustri kopi bubuk organik di Desa Gunung Terang Kecamatan Way Tenong Kabupaten Lampung Barat

Hasil penelitian ini diharapkan menjadi bahan informasi dan manfaat bagi pihak-pihak berkepentingan dalam bidang agroindustri kopi bubuk organik. Selain itu, hasil ini juga diharapkan dapat menjadi bahan referensi untuk penelitian selanjutnya dan sebagai pustaka ilmiah

\section{KERANGKA TEORITIS}

\section{A. Tinjauan Pustaka}

\section{B. Model Pendekatan}

Model pendekatan yang digunakan dalam penelitian ini adalah model pendekatan secara diagramatis pada gambar 1 berikut :

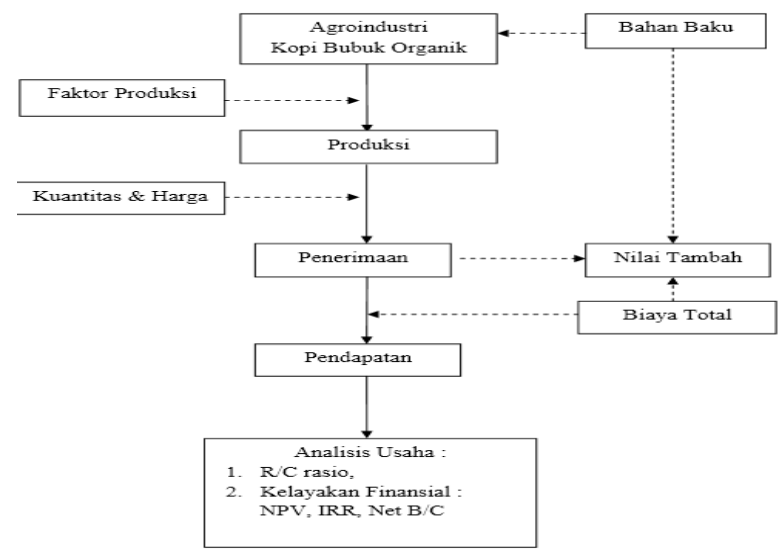

Keterangan:

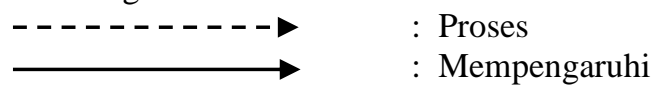

Sedangakan secara matematis dapat dilihat sebagai berikut :
1) Untuk mengetahui biaya produksi dengan rumus (Suratiyah, 2006) :

$\mathrm{TC}=\mathrm{FC}+\mathrm{VC}$

Dimana :

$\mathrm{TC}=$ Total Cost (Biaya Produksi)

$\mathrm{FC}=$ Fixed Cost (Biaya Tetap)

$\mathrm{VC}=$ Variable Cost (Biaya Variabel $)$

2) Untuk mengetahui penerimaan, digunakan rumus (Suratiyah, 2006) :

$\mathrm{TR}=\mathrm{Y} \times \mathrm{P}$

Dimana :

$\mathrm{R}=$ Total Revenues/Penerimaan

$\mathrm{Y}=$ Yield/Hasil Produksi

$\mathrm{P}=$ Price/Harga Jual

3) Untuk menghitung pendapatan, digunakan rumus (Suratiyah, 2006) :

$\mathrm{I}=\mathrm{TR}-\mathrm{TC}$

Dimana :

I = Income/Pendapatan

$\mathrm{TR}=$ Total Revenue $/$ Penerimaan

$\mathrm{TC}=$ Total Cost $/$ Total Biaya Produksi

4) Untuk menghitung nilai tambah digunakan rumus (Ariadi dan Relawati, 2011):

$\mathrm{NT}=\mathrm{TR}-\mathrm{IC}$

Keterangan :

$\mathrm{NT}=$ Nilai Tambah $(\mathrm{Rp} / \mathrm{Kg})$

$\mathrm{TR}=$ Total Revenue $(\mathrm{Rp} / \mathrm{Kg})$

IC = Intermediate Cost/Biaya antara $(\mathrm{Rp} / \mathrm{Kg})$

IC = (Biaya Produksi - Biaya tenaga kerja)

5) Untuk menghitung NPV maka digunakan rumus (Ibrahim, 2009) :

$\mathrm{NPV}=\Sigma \mathrm{NB}$

Keterangan :

NPV $=$ Net Present Value / Nilai Kini Bersih

$\mathrm{N} \overline{\mathrm{B}}=$ Net Benefit yang telah didiscount factor

Dengan kriteria :

NPV > 0 : maka usaha layak (feasible)

$\mathrm{NPV}<0$ : maka usaha tidak layak untuk dilaksanakan

NPV $=0$ : maka usaha dalam keadaan impas

6) Untuk menghitung Internal Rate Ratio (IRR) digunakan rumus (Ibrahim, 2009)

$I R R=i_{1}+\frac{N P V_{1}}{\left(N P V_{1}-N P V_{3}\right.} \times\left(i_{2}-i\right)$

Dimana :

$\mathrm{NPV}_{1}=\mathrm{NPV}$ pada tingkat discount rate tertinggi (positif).

$\mathrm{NPV}_{2}=\mathrm{NPV}$ pada tingkat discount rate terendah (negatif).

$\mathrm{i}_{1} \quad=$ Discount rate tertinggi

$\mathrm{i}_{2} \quad=$ Discount rate terendah

Dengan kriteria :

IRR > SOCC : maka usaha layak (feasible)

IRR < SOCC : maka usaha tidak layak (feasible)

7) Untuk menghitung nilai net $\mathrm{B} / \mathrm{C}$ ratio maka digunakan rumus (Ibrahim, 2009) :

Net B/C $=\frac{\sum \mathrm{NB}(+)}{\Sigma \mathrm{NB}(-)}$ 
Dimana :

$\Sigma \mathrm{NB}(+)=$ Net Benefit yang telah didiscount positif

$\Sigma$ NB (-) = Net Benefit yang telah didiscount negatif

Dengan kriteria :

Net $\mathrm{B} / \mathrm{C}>1$ Berarti usahatani layak dikembangkan

Net $B / C=1$ Berarti usahatani tidak untung dan tidak rugi (impas)

Net B/C $<1$ Berarti usahatani tidak layak

\section{B. Hipotesis}

Berdasarkan tujuan penelitian di atas, maka dapat ditarik suatu hipotesis dalam penelitian ini adalah sebagai berikut:

1. Diduga bahwa penerimaan yang diterima lebih besar dari pada biaya produksi sehingga diperoleh pendapatan pada agroindustri kopi bubuk organik di Desa Gunung Terang Kecamatan Way Tenong Kabupaten Lampung Barat.

2. Diduga bahwa agroindustri kopi bubuk organik di Desa Gunung Terang Kecamatan Way Tenong Lampung Barat dapat memberikan nilai tambah.

3. Diduga bahwa agroindustri kopi bubuk organik di Desa Gunung Terang Kecamatan Way Tenong Kabupaten Lampung Barat layak secara finansial.

\section{Batasan-Batasan}

1. Responden adalah adalah pengusaha yang melakukan pengolahan biji kopi organik menjadi bubuk kopi organik di Desa Gunung Terang Kecamatan Way Tenong Kabupaten Lampung Barat.

2. Kopi Bubuk Organik adalah kopi bubuk yang dihasilkan dari proses penggilingan biji kopi organik sebagai bahan baku utama minuman kopi.

3. Produksi adalah banyaknya hasil dari kegiatan agroindustri pengolahan biji kopi menjadi kopi bubuk organik yang dihasilkan dalam satu kali proses produksi (Kg/Proses).

4. Proses produksi adalah waktu yang dibutuhkan dalam mengolah biji kopi organik menjadi kopi bubuk organik yaitu rata-rata selama 1 tahun.

5. Harga adalah harga jual kopi bubuk organik yang diterima oleh pengusaha dan diukur dalam satuan rupiah $(\mathrm{Rp} / \mathrm{Kg})$.

6. Biaya tetap adalah biaya yang besarnya tidak dipengaruhi oleh jumlah produksi dan tidak habis dalam satu kali proses produksi, meliputi biaya penyusutan peralatan, dan biaya sewa tempat (Rp/Proses).

7. Biaya variabel adalah biaya yang besarnya dipengaruhi besar kecilnya produksi dan habis dalam satu kali proses produksi, meliputi biaya bahan baku dan biaya tenaga kerja (Rp/Proses).

8. Biaya total adalah semua biaya yang digunakan dalam agroindustri pengolahan kopi bubuk organik, meliputi biaya tetap ditambah biaya variabel ( $\mathrm{Rp} /$ Proses).
9. Penerimaan adalah jumlah penerimaan yang diperoleh dari penjualan kopi bubuk organik yang diperoleh dari perkalian antara jumlah produk kopi bubuk organik yang terjual dengan harga jual per kilogram (Rp/Proses).

10. Pendapatan adalah balas jasa yang diterima pengusaha agroindustri kopi bubuk organik dari pekerjaan dan pengelolaan agroindustri kopi bubuk organik. Besarnya pendapatan dihitung dengan mengurangi penerimaan agroindustri kopi bubuk organik dengan biaya-biaya yang dikeluarkan, diukur dalam satuan rupiah (Rp/Proses).

11. Nilai tambah adalah selisih antara produksi (output) yang dihasilkan dengan biaya antara/intermediate cost $(\mathrm{Rp} / \mathrm{Kg})$

12. Biaya antara (intermediate cost) adalah biaya yang dikeluarkan dalam proses produksi seperti bahan baku dan input lainnya selain biaya tenaga kerja

13. Kelayakan usaha adalah uji tingkat kelayakan finansial dihitung dengan menggunakan rumus : NPV, IRR dan Net B/C.

14. Net Present Value (NPV) adalah suatu analisis yang digunakan untuk menghitung selisih antara present value dari penerimaan dengan present value dari biaya-biaya yang telah dikeluarkan, diukur dalam satuan rupiah ( $\mathrm{Rp})$

15. Internal Rate of Return (IRR) adalah analisis yang digunakan untuk mengetahui tingkat keuntungan atau investasi bersih dalam suatu proyek. IRR merupakan tingkat bunga (discount rate) yang dapat membuat besarnya NPV proyek sama dengan nol (0), diukur dalam satuan (\%).

16. Net Benefit Cost (Net B/C) adalah perbandingan antara present value net benefit yang positif dengan present value net benefit yang negatif.

\section{PELAKSANAAN PENELITIAN}

\section{A. Tempat dan Waktu}

Penelitian ini akan dilaksanakan di Desa Gunung Terang Kecamatan Way Tenong Kabupaten Lampung Barat. Lokasi penelitian dipilih dengan sengaja (purposive) yaitu dengan pertimbangan bahwa di Desa Gunung Terang Kecamatan Way Tenong Kabupaten Lampung Barat terdapat salah satu pengusaha sekaligus pemilik agroindustri yang mengolah kopi organik menjadi kopi bubuk organik. Penelitian akan dilaksanakan pada Bulan Mei 2019.

\section{B. Metode Penelitian dan Penarikan Contoh}

Metode penelitian yang akan digunakan dalam penelitian ini adalah metode studi kasus kasus (case study) yang bertujuan untuk mendapatkan gambaran yang ada di lapangan dengan benar. Metode studi kasus adalah penelitian terhadap suatu kasus secara intensif dan mendalam (Nazir, 2003). 
Adapun metode penarikan contoh yang akan digunakan dalam penelitian ini adalah secara sengaja (Purposive Sampling). Purposive sampling ialah teknik sampling yang digunakan peneliti dengan pertimbangan - pertimbangan tertentu di dalam pengambilan sampelny (Nazir, 003). Dalam penelitian ini responden berjumlah 1 orang yaitu Bapak Suparyoto yang memiliki perusahaan " Waroeng Organik" yang mengolah biji kopi organik menjadi bubuk kopi organik. Adapun pertimbangan peneliti adalah karena perusahaan Waroeng Organik telah berdiri sejak tahun 2006 sekaligus perintis (pioneer) usaha kopi bubuk organik di Desa Gunung Terang.

\section{Metode Pengumpulan Data}

Jenis data yang dikumpulkan pada penelitian ini adalah data primer dan data sekunder. Data primer diperoleh dengan melakukan wawancara langsung terhadap pengusaha sekaligus pemilik agroindustri kopi bubuk Waroeng Organik di lokasi penelitian dengan menggunakan kuisioner dengan tujuan agar pertanyaan yang diajukan terstruktur dan lengkap sekaligus melakukan pengamatan (observasi) langsung di lapangan. Sedangkan data sekunder diperoleh dari instansi-instansi yang terkait serta literatur yang relevan dengan penelitian ini.

\section{Metode Pengolahan Data}

Data yang diperoleh dari lapangan diolah dan dianalisis secara matematis dengan analisis finansial. Untuk menjawab tujuan penelitian yang pertama yaitu untuk menghitung biaya, penerimaan dan pendapatan agroindustri kopi bubuk organik di Desa Gunung Terang Kecamatan Way Tenong Kabupaten Lampung Barat dihitung dengan menggunakan rumus :

1. Untuk mengetahui biaya produksi digunakan rumus (Soekartawi, 2002) :

$\mathrm{TC}=\mathrm{FC}+\mathrm{VC}$

Dimana :

$\mathrm{TC}=$ Total Cost/Total Biaya Produksi (Rp/Proses)

$\mathrm{FC}=$ Fixed Cost/Biaya Tetap $(\mathrm{Rp} /$ Proses $)$

$\mathrm{VC}=$ Variable Cost/Biaya Variabel (Rp/ Proses)

2. Untuk menghitung penerimaan, digunakan rumus (Soekartawi, 2002) :

$\mathrm{TR}=\mathrm{Py} \mathrm{x} \mathrm{Y}$

Dimana :

$\mathrm{TR}=$ Total Revenues $/$ Penerimaan $(\mathrm{Rp} / \mathrm{Proses})$

$\mathrm{Py}=$ Price Yield/Harga Jual Produk $(\mathrm{Rp} / \mathrm{Kg})$

$\mathrm{Y}=$ Yield $/$ Hasil produksi (Kg/Proses)

3. Untuk menghitung pendapatan, digunakan rumus (Suratiyah, 2006) :

$\mathrm{I}=\mathrm{TR}-\mathrm{TC}$

Dimana :

$\mathrm{I} \quad=$ Income/Pendapatan $(\mathrm{Rp} / \mathrm{Proses})$

$\mathrm{TR}=$ Total Revenue/Penerimaan (Rp/Proses)

$\mathrm{TC}=$ Total Cost/Total Biaya Produksi (RpProses)

4. $\mathrm{R} / \mathrm{C}$ ratio dihitung dengan menggunakan rumus (Sokartawi, 2002) :

\section{TR \\ R/C Ratio $=\square \quad \ldots \ldots \ldots \ldots \ldots \ldots \ldots . .4)$ \\ Dimana : $\quad \mathrm{TC}$ \\ $\mathrm{TR}=$ Total Revenue/Total Penerimaan (Rp/proses) \\ $\mathrm{TC}=$ Total Cost/Biaya Total (Rp/proses) \\ Dengan ketentuan : \\ R/C Ratio > 1 Berarti usaha menguntungkan \\ $\mathrm{R} / \mathrm{C}$ Ratio $=1$ Berarti usaha tidak untung dan tidak rugi (impas) \\ R/C Ratio < 1 Berarti usaha tidak menguntungkan (rugi)}

Untuk menjawab tujuan penelitian yang kedua yaitu untuk menganalisis nilai tambah agroindustri kopi bubuk organik di Desa Gunung Terang Kecamatan Way Tenong Kabupaten Lampung Barat dihitung dengan menggunakan rumus :

5. Untuk menghitung nilai tambah digunakan rumus (Yudi, 2010) :

$\mathrm{NT}=\mathrm{TR}-\mathrm{IC}$

Keterangan :

$\mathrm{NT}=$ Nilai Tambah $(\mathrm{Rp} / \mathrm{Kg})$

$\mathrm{TR}=$ Total Revenue/Total Penerimaan $(\mathrm{Rp})$

$\mathrm{IC}=$ Intermediate Cost/Biaya antara ( $\mathrm{Rp})$

Untuk menjawab tujuan penelitian yang ketiga yaitu untuk menganalisis kelayakan finansial usaha agroindustri kopi bubuk organik di Desa Gunung Terang Kecamatan Way Tenong Kabupaten Lampung Barat dihitung dengan menggunakan rumus :

6. Untuk menghitung NPV maka digunakan rumus (Ibrahim, 2009) :

$\mathrm{NPV}=\Sigma \mathrm{NB}$

Keterangan :

$\mathrm{NPV}=$ Net Present Value / Nilai Kini Bersih

$\mathrm{NB}=$ Net Benefit yang telah didiscount factor

Dengan kriteria :

NPV > 0 maka usaha layak (feasible)

$\mathrm{NPV}<0$ maka usaha tidak layak untuk dilaksanakan

$\mathrm{NPV}=0$ maka usaha dalam keadaan impas

7. Untuk menghitung Internal Rate of Return (IRR)

maka digunakan rumus :

(Ibrahim, 2009).

$I R R=i_{1}+\frac{N P V_{1}}{\left(N P V_{1}-N P V_{2}\right)} \times\left(i_{2}-i_{1}\right) \ldots \ldots . .$.

Dimana :

$\mathrm{NPV}_{1}=\mathrm{NPV}$ pada tingkat discount rate tertinggi (positif).

$\mathrm{NPV}_{2}=\mathrm{NPV}$ pada tingkat discount rate terendah (negatif).

$\mathrm{i}_{1} \quad=$ Discount rate tertinggi

$\mathrm{i}_{2} \quad=$ Discount rate terendah

SOCC = Social Opportunity Cost of Capital (Tingkat Bunga Berlaku Kini)

Dengan kriteria :

IRR > SOCC : maka usaha layak

IRR < SOCC : maka usaha tidak layak

8. Untuk menghitung nilai net $\mathrm{B} / \mathrm{C}$ maka digunakan rumus (Ibrahim, 2009) : 
Net $\mathrm{B} / \mathrm{C}=\frac{\sum \mathrm{NB}(+)}{\sum \mathrm{NB}(-)}$

Dimana :

$\Sigma \mathrm{NB}(+)=$ Net Benefit yang telah didiscount positif

$\Sigma$ NB (-) = Net Benefit yang telah didiscount negatif

Dengan kriteria :

Net $\mathrm{B} / \mathrm{C}>1$ Berarti usaha layak dikembangkan

Net $B / C=1$ Berarti usaha tidak untung dan tidak rugi (impas)

Net B/C $<1$ Berarti usaha tidak layak

\section{HASIL DAN PEMBAHASAN}

\section{A. Analisis Biaya Agroindustri Kopi Bubuk Organik}

Analisa usaha digunakan sebagai tolak ukur suatu usaha apakah menguntungkan atau tidak dan apakah usaha tersebut layak untuk dikembangkan atau tidak. Biaya dalam kegiatan usaha dikeluarkan oleh responden dengan tujuan untuk menghasilkan pendapatan yang tinggi bagi usaha yang dikerjakan, dengan mengeluarkan biaya maka pelaku usaha mengharapkan pendapatan yang setinggi-tingginya melalui peningkatan produksi. Biaya dalam kegiatan usaha terdiri dari biaya tetap (fixed cost) dan biaya variabel (variabel cost).

Biaya tetap (fixed cost) adalah biaya yang relatif tetap jumlahnya dan harus dikeluarkan walaupun produk yang dihasilkan banyak atau sedikit. Biaya tidak tetap (variable cost) adalah biaya yang sifatnya berubah-ubah tergantung dari besar kecilnya produksi yang dihasilkan. Dalam hasil penelitian yang dikelompokkan ke dalam biaya tetap di antaranya adalah biaya sewa tanah dan biaya penyusutan alat. Sedangkan untuk biaya variabel terdiri dari biaya pembelian sarana produksi pertanian dan biaya tenaga kerja.

Berikut ini merupakan komponen biaya yang dikeluarkan oleh agroindustri pengolahan kopi bubuk organik di Desa Gunung Terang Kecamatan Way Tenong Kabupaten Lampung Barat :

\section{Biaya Tetap (Fixed Cost)}

Biaya tetap yang digunakan oleh agroindustri pengolahan kopi bubuk organik di antaranya meliputi biaya sewa lahan dan biaya penyusutan peralatan yang dapat dilihat pada tabel 4 sebagai berikut :

Tabel 4. Biaya Tetap Agroindustri Kopi Bubuk Organik di Desa Gunung Terang Kecamatan Way Tenong Kabupaten Lampung Barat, 2019.

\begin{tabular}{cccc}
\hline No & Komponen Biaya & \multicolumn{2}{c}{ Nilai (Rp/Proses) } \\
\hline 1. & Sewa Tempat Usaha & $\mathbf{1 6 . 6 6 7}$ & \\
2. & Penyusutan Alat & $\mathbf{8 1 . 5 2 5}$ & 8,025 \\
& & &
\end{tabular}

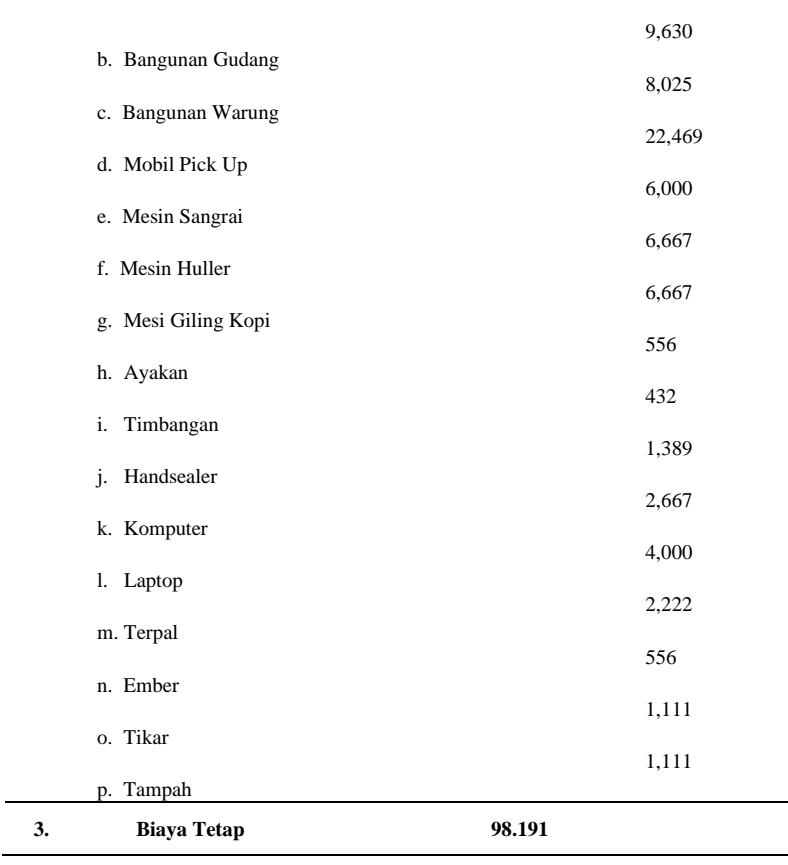

Sumber : Olahan Data Primer, 2019.

Berdasarkan data tabel di atas diketahui bahwa biaya sewa tempat usaha agroindustri kopi bubuk organik di Desa Gunung Terang Kecamatan Way Tenong Kabupaten Lampung Barat dalam satu kali proses produksi (2 hari) adalah sebesar Rp 16.667 atau sebesar Rp 250.000/Bulan. Adapun rata-rata biaya penyusutan alat agroindustri kopi bubuk organik dalam satu kali proses produksi adalah sebesar Rp 81.525 atau sebesar Rp 1.222.870/Bulan.

Biaya tetap agroindustri kopi bubuk organik di Desa Gunung Terang Kecamatan Way Tenong Kabupaten Lampung Barat yang terdiri dari biaya sewa lahan dan biaya penyusutan peralatan dalam satu kali proses produksi rata-rata adalah sebesar Rp 98.191 atau rata-rata sebesar Rp 1.472.870/Bulan.

\section{Biaya Variabel (Variabel Cost)}

Biaya variabel adalah biaya yang digunakan dalam kegiatan usaha yang tergantung dari besar kecilnya produksi yang dihasilkan dan biasanya habis dalam satu kali proses produksi. Biaya variabel yang digunakan dalam agroindustri kopi bubuk organik di Desa Gunung Terang Kecamatan Way Tenong Kabupaten Lampung Barat terdiri atas biaya pembelian bahan baku dan biaya tenaga kerja. Biaya bahan baku agroindustri kopi bubuk organik digunakan untuk pembelian biji kopi organik kering, kayu bakar, plastik kemasan, listrik, telepon, air bersih, dan bahan bakar.

Bahan bakar yang digunakan agroindustri kopi bubuk organik untuk mengolah biji kopi organik kering menjadi kopi bubuk organik adalah kayu bakar dan solar. Kayu bakar digunakan untuk melakukan penyangraian biji kopi organik kering, sedangkan solar digunakan untuk menjalankan alat-alat agroindustri. Air bersih digunakan untuk membersihkan alat-alat produksi yang perlu 
dibersihkan. Telepon digunakan untuk kegiatan operasional agroindustri. Besarnya upah tenaga kerja tidak dibedakan antara tenaga kerja dalam keluarga maupun tenaga kerja luar keluarga. Hal ini dilakukan dengan tujuan agar tidak ada kesenjangan upah. Adapun besarnya biaya variabel agroindustri kopi bubuk organik terdiri dari biaya bahan baku dan biaya tenaga kerja dapat dilihat pada tabel 5 berikut :

Tabel 5. Biaya Variabel Agroindustri Kopi Bubuk Organik di Desa Gunung Terang Kecamatan Way Tenong Kabupaten Lampung Barat, 2019.

\begin{tabular}{lll}
\hline No & \multicolumn{1}{c}{ Komponen Biaya } & Nilai (Rp/Proses) \\
\hline 1. & Biaya Bahan Baku & $\mathbf{2 . 6 6 7 . 0 0 0}$ \\
& a. Biji Kopi Organik & 2.275 .000 \\
b. Kayu Bakar & 100.000 \\
c. Plastik Kemasan 1 Kg & 30.000 \\
d. $\quad$ Plastik Kemasan & 0,5 \\
Kg & 45.000 \\
e. $\quad$ Plastik Kemasan & 0,25 \\
Kg & 90.000 \\
f. Listrik & 25.000 \\
g. Air Bersih & 7.000 \\
h. Telepon & 15.000 \\
i. Solar & 35.000 \\
j. Bensin & 45.000 \\
Biaya Tenaga Kerja & $\mathbf{9 1 0 . 0 0 0}$ \\
\hline 3. & Biaya Variabel & $\mathbf{3 . 5 7 7 . 0 0 0}$ \\
\hline &
\end{tabular}

Sumber : Olahan Data Primer, 2019.

Berdasarkan hasil pada tabel 5, dapat diketahui bahwa rata-rata besarnya biaya pembelian bahan baku diantaranya untuk pembelian biji kopi organik kering, kayu bakar, plastik kemasan, listrik, air bersih, telepon, solar dan bensin dalam satu kali proses produksi ratarata adalah sebesar $\mathrm{Rp}$ 2.667.000. Besarnya biaya tenaga kerja agroindustri kopi bubuk organik dalam satu kali proses produksi rata-rata adalah sebesar Rp 910.000. Besarnya biaya variabel usaha pembuatan kopi bubuk organik di Gunung Terang Kecamatan Way Tenong Kabupaten Lampung Barat yang terdiri dari biaya bahan baku dan biaya tenaga kerja dalam satu kali proses produksi adalah sebesar Rp 3.577.000 atau rata-rata sebesar Rp 67.305.000/Bulan.

\section{Biaya Total (Total Cost)}

Biaya total dalam kegiatan agroindustri kopi bubuk organik terdiri dari biaya tetap ditambah dengan biaya variabel. Besarnya biaya total agroindustri kopi bubuk organik di Desa Gunung
Terang Kecamatan Way Tenong Kabupaten Lampung Barat disajikan pada tabel 6 berikut :

Tabel 6. Biaya Total Agroindustri Kopi Bubuk Organik di Desa Gunung Terang Kecamatan Way Tenong Kabupaten Lampung Barat, 2019.

\begin{tabular}{clr}
\hline No & \multicolumn{1}{c}{ Komponen Biaya } & $\begin{array}{c}\text { Nilai } \\
\text { (Rp/Proses) }\end{array}$ \\
\hline $1 . \quad$ Biaya Tetap & 16.667 \\
& a. Sewa Lahan & 81.525 \\
& b. Penyusutan Peralatan & $\mathbf{9 8 . 1 9 1}$ \\
& c. Jumlah Biaya Tetap & \\
2. Biaya Variabel & 2.667 .000 \\
& a. Biaya Bahan Baku & 910.000 \\
& b. Biaya Tenaga Kerja & $\mathbf{3 . 5 7 7 . 0 0 0}$ \\
\hline & c. Jumlah Biaya Variabel & $\mathbf{3 . 6 7 5 . 1 9 1}$
\end{tabular}

Sumber : Olahan Data Primer, 2019.

Berdasarkan hasil pada tabel 6, dapat diketahui bahwa biaya tetap agroindustri kopi bubuk organik di Desa Gunung Terang yang terdiri dari biaya sewa lahan dan biaya penyusutan peralatan dalam satu kali proses produksi rata-rata adalah sebesar Rp 98.191. Biaya variabel yang terdiri dari biaya bahan baku dan biaya tenaga kerja dalam satu kali proses produksi ratarata adalah sebesar Rp 3.577.00, sehingga diperoleh biaya total produksi agroindustri kopi bubuk organik di Desa Gunung Terang Kecamatan Way Tenong Lampung Barat yang terdiri biaya tetap dan biaya variabel dalam satu kali proses produksi rata-rata adalah sebesar Rp 3.675.191 atau rata-rata sebesar Rp 68.777.870/Bulan

\section{B. Produksi, Harga, Penerimaan dan Pendapatan}

Hasil akhir atau produksi dalam agroindustri kopi bubuk organik adalah berupa kopi bubuk organik. Produksi adalah jumlah kopi bubuk organik yang dihasilkan selama satu kali proses produksi dan diukur dalam satuan kilogram. Satu kali proses proses membutuhkan waktu rata-rata selama 2 (dua) hari. Rata-rata produksi kopi bubuk organik yang dihasilkan dalam satu kali proses produksi adalah sebanyak $50 \mathrm{Kg}$ atau rata - rata sebanyak $750 \mathrm{Kg} /$ Bulan.

Terdapat 3 kemasan kopi bubuk organik yang biasa dihasilkan yaitu kemasan $1 \mathrm{Kg}$ dengan harga rata-rata $\mathrm{Rp} 85.000$, kemasan $0,5 \mathrm{Kg}$ dengan harga rata-rata $\mathrm{Rp} 45.000$ dan kemasan $0,25 \mathrm{Kg}$ dengan harga rata-rata $\mathrm{Rp}$ 25.000. Apabila dibuat rata-rata harga jual kopi bubuk organik maka diperoleh harga jual adalah sebesar Rp 91.000/Kg dan produksi kopi bubuk organik sebanyak $50 \mathrm{Kg}$.

Penerimaan merupakan perkalian antara produk kopi bubuk organik yang dihasilkan dengan harga jual kopi bubuk organik. Berdasarkan hasil analisis maka dihasilkan rata-rata penerimaan sebesar Rp 4.450.000/Proses atau rata-rata sebesar $\mathrm{Rp}$ 68.250.000/Bulan. Pendapatan usaha merupakan hasil dari penerimaan dikurangi dengan biaya produksi. Rata-rata total biaya produksi usaha pembuatan kopi bubuk organik dalam satu kali proses adalah sebesar 
Rp 3.675.191 atau sebesar Rp 55.127.870/Bulan. Ratarata penerimaan usaha pembuatan kopi bubuk organik adalah sebesar Rp 4.450.000/Proses atau Rp 68.250.000/Bulan sehingga pendapatan usaha pembuatan kopi bubuk organik di Gunung Terang Kecamatan Way Tenong Kabupaten Lampung Barat dalam satu kali proses produksi rata-rata adalah sebesar $\mathrm{Rp} \quad 874.809$ atau rata-rata sebesar $\mathrm{Rp}$ 13.122.130/Bulan.

Tabel 7. Produksi, Harga, Penerimaan dan Pendapatan Agroindustri Kopi Bubuk Organik di Desa Gunung Terang Kecamatan Way Tenong Kabupaten Lampung Barat, 2019.

\begin{tabular}{|c|c|c|c|}
\hline No & Uraian & Satuan & Nilai \\
\hline \multirow[t]{4}{*}{1.} & Produksi & & \\
\hline & a. Kopi Bubuk Kemasan $1 \mathrm{Kg}$ & Bks/Proses & 20 \\
\hline & b. Kopi Bubuk Kemasan $0,5 \mathrm{Kg}$ & Bks/Proses & 30 \\
\hline & c. Kopi Bubuk Kemasan 0,25 Kg & Bks/Proses & 60 \\
\hline \multirow[t]{4}{*}{2.} & Harga & & \\
\hline & a. Kopi Bubuk Kemasan $1 \mathrm{Kg}$ & $\mathrm{Rp} / \mathrm{Bks}$ & 85.000 \\
\hline & b. Kopi Bubuk Kemasan 0,5 Kg & $\mathrm{Rp} / \mathrm{Bks}$ & 45.000 \\
\hline & c. Kopi Bubuk Kemasan 0,25 Kg & $\mathrm{Rp} / \mathrm{Bks}$ & 25.000 \\
\hline \multirow[t]{4}{*}{3.} & Penerimaan & & \\
\hline & a. Kopi Bubuk Kemasan $1 \mathrm{Kg}$ & Rp/Proses & 1.700 .000 \\
\hline & b. Kopi Bubuk Kemasan 0,5 Kg & Rp/Proses & 1.350 .000 \\
\hline & c. Kopi Bubuk Kemasan 0,25 Kg & Rp/Proses & 1.500 .000 \\
\hline 4. & Total Penerimaan & Rp/Proses & 4.550 .000 \\
\hline 5. & Total Biaya Produksi & Rp/Proses & 3.675 .191 \\
\hline 6. & Pendapatan & & 879.809 \\
\hline 7. & R/C Rasio & & 1,24 \\
\hline
\end{tabular}

Sumber : Olahan Data Primer, 2019.

Tingkat keuntungan suatu analisis usaha dapat dinyatakan melalui $\mathrm{R} / \mathrm{C}$ rasio (revenue cost ratio). Analisis R/C rasio dapat digunakan untuk mengetahui rasio tingkat keuntungan suatu usaha yang dijalankan. Berdasarkan hasil perhitungan pada Tabel 15 diperoleh bahwa nilai $\mathrm{R} / \mathrm{C}$ rasio usaha pembuatan kopi bubuk organik adalah sebesar 1,24. Nilai R/C rasio sebesar 1,24 artinya bahwa setiap satu rupiah biaya yang dikeluarkan untuk usaha pembuatan kopi bubuk organik maka akan menghasilkan penerimaan sebesar Rp 1,24. Karena nilai R/C > 1, ini menunjukkan bahwa usaha pembuatan kopi bubuk organik di Desa Gunung Terang Kecamatan Way Tenong Kabupaten Lampung Barat menguntungkan secara finansial.

\section{Analisis Nilai Tambah Agroindustri Kopi Bubuk Organik}

Nilai tambah suatu produk adalah hasil dari nilai produk akhir dikurangi dengan biaya antara yang terdiri dari biaya bahan baku dan bahan penolong tanpa biaya tenaga kerja. Nilai tambah merupakan nilai yang ditambahkan kepada barang dan jasa yang dipakai oleh unit produksi dalam proses produksi sebagai biaya antara (Tarigan, 2004). Proses pengolahan kopi bubuk organik akan memberikan nilai tambah bagi kopi itu sendiri. Sedangkan untuk menghasilkan produk berupa kopi bubuk organik tersebut diperlukan faktor-faktor produksi lain mulai dari tenaga kerja, peralatan produksi, bahan-bahan tambahan dan lain-lain.

Tabel 8. Rata-rata Nilai Tambah Agroindustri Kopi Bubuk Organik di Desa Gunung Terang Kecamatan Way Tenong Kabupaten Lampung Barat, 2019.

\begin{tabular}{clll}
\hline No & \multicolumn{1}{c}{ Uraian } & \multicolumn{1}{c}{ Satuan } & \multicolumn{1}{c}{ Nilai } \\
\hline 1. & Kebutuhan Biji Kopi Organik & Kg/Proses & \multicolumn{2}{l}{65} \\
2. & Produksi Kopi Bubuk Organik & Kg/Proses & \multicolumn{2}{l}{50} \\
3. & Harga Jual Kopi Bubuk Organik & Rp/Kg & \multicolumn{2}{l}{91.000} \\
4. & Nilai Akhir Kopi Bubuk Organik & Rp/Proses & 4.550 .000 \\
5. & Total Biaya Produksi & Rp/Proses & 3.675 .191 \\
6. & Biaya Tenaga Kerja & Rp/Proses & 910.000 \\
7. & Biaya Antara (Intermediate Cost) & Rp/Proses & 2.576 .191 \\
8. & Nilai Tambah & Rp/Proses & 1.784 .809 \\
9. & Nilai Tambah (Per Kg Kopi Organik) & Rp/Kg & 27.459 \\
\hline
\end{tabular}

Sumber : Olahan Data Primer, 2019.

Nilai akhir kopi bubuk organik atau penerimaan kopi bubuk organik diperoleh dari produksi kopi bubuk organik (50 Kg/proses) dikali dengan harga jual kopi bubuk organik ( $\mathrm{Rp} 91.000 / \mathrm{Kg}$ ) sehingga diperoleh nilai akhir kopi bubuk organik adalah sebesar Rp 4.550.000/Proses. Biaya tenaga kerja diperoleh dari pembayaran upah tenaga kerja yang rata-rata berasal dari dalam keluarga sendiri yaitu sebesar Rp 910.000/proses. Biaya antara atau Intermediate Cost (IC) diperoleh dari total biaya produksi (Rp 3.675.191/Proses) dikurangi dengan biaya tenaga kerja (Rp 910.000/Proses) sehingga diperoleh nilai rata-rata biaya antara adalah sebesar Rp 1.576.191/Proses.

Nilai tambah diperoleh dari total penerimaan atau nilai akhir kopi bubuk organik sebesar 4.550.000/Proses dikurangi dengan nilai biaya antara yaitu sebesar Rp 1.576.191/Proses sehingga diperoleh nilai tambah agroindustri kopi bubuk organik di Gunung Terang Kecamatan Way Tenong Kabupaten Lampung Barat adalah sebesar Rp 1.784.809/Proses produksi atau diperoleh nilai tambah per $\mathrm{Kg}$ penjualan kopi bubuk organik adalah sebesar Rp 27.459. Hal ini menunjukan bahwa setiap $1 \mathrm{Kg}$ kopi bubuk organik akan memberikan nilai tambah sebesar Rp 27.459. Hal ini menunjukan bahwa agroindustri pengolahan kopi bubuk organik di Gunung Terang Kecamatan Way Tenong Kabupaten Lampung Barat dapat memberikan nilai tambah secara financial bagi pelaku usaha.

\section{Analisis Kelayakan Aspek Finansial}

Analisis kelayakan usaha agribinis adalah upaya untuk mengetahui tingkat kelayakan atau kepantasan 
untuk dikerjakan dari suatu usaha, dengan melihat beberapa parameter atau kriteria kelayakan tertentu. Studi kelayakan merupakan bahan pertimbangan dalam mengambil suatu keputusan, menerima atau menolak suatu usaha yang direncanakan. Perhitungan analisis finansial menggunakan tingkat suku bunga deposito selama 1 tahun yaitu rata-rata sebesar 7\%. Dengan menggunakan suku bunga acuan tersebut akan didapat nilai Compounding Factor

\section{Analisis NPV}

Net Present Value (NPV) atau nilai sekarang bersih adalah analisis manfaat finansial yang digunakan untuk mengukur layak tidaknya suatu usaha dilaksanakan dilihat dari nilai sekarang (present value). Kriteria kelayakan dari usaha ini adalah : proyek layak jika NPV lebih besar dari nol (positif) dan sebaliknya proyek tidak layak jika NPV nilainya lebih kecil dari nol (negatif).

Tabel 9. Analisis NPV Agroindustri Kopi Bubuk Organik di Desa Gunung Terang Kecamatan Way Tenong Lampung Barat, Tahun 20092019.

\begin{tabular}{|c|c|c|c|c|c|c|c|c|}
\hline Tahun & Tahun Ke & Biaya Investasi & B. Operasional & Biaya Total & Penerimaan & Pendapatan & CF $7 \%$ & Present Value $7 \%$ \\
\hline 2009 & 10 & $161,081,000$ & $131,340,000$ & $292,421,000$ & $171,000,000$ & $-121,421,000$ & 1.9672 & $-238,853,485$ \\
\hline 2010 & 9 & 550,000 & $131,340,000$ & $131,890,000$ & $171,000,000$ & $39,110,000$ & 1.8385 & $71,902,140$ \\
\hline 2011 & 8 & $1,250,000$ & $157,320,000$ & $158,570,000$ & $198,000,000$ & $39,430,000$ & 1.7182 & $67,748,081$ \\
\hline 2012 & 7 & $1,225,000$ & $234,440,000$ & $236,065,000$ & $297,000,000$ & $60,935,000$ & 1.6058 & $97,848,294$ \\
\hline 2013 & 6 & $2,125,000$ & $234,840,000$ & $236,965,000$ & $297,000,000$ & $60,035,000$ & 1.5007 & $90,096,347$ \\
\hline 2014 & 5 & 225,000 & 40,000 & $300,365,000$ & $351,000,000$ & $50,635,000$ & 1.4026 & $71,018,207$ \\
\hline 2015 & 4 & $2,225,000$ & $333,066,000$ & $335,291,000$ & $414,000,000$ & $78,709,000$ & 1.3108 & $103,171,443$ \\
\hline 2016 & 3 & 900,000 & $351,666,000$ & $352,566,000$ & $452,250,000$ & $99,684,000$ & 1.2250 & $122,117,186$ \\
\hline 2017 & 2 & $2,831,000$ & $484,398,300$ & $487,229,300$ & $573,750,000$ & $86,520,700$ & 1.1449 & $99,057,549$ \\
\hline 2018 & 1 & $2,600,000$ & $565,687,800$ & $568,287,800$ & $686,250,000$ & $117,962,200$ & 1.0700 & $126,219,554$ \\
\hline \multirow[t]{2}{*}{2019} & 0 & $36,900,000$ & $351,180,000$ & $388,080,000$ & $409,500,000$ & $21,420,000$ & 1.0000 & $21,420,000$ \\
\hline & & $237,912,000$ & $3,249,818,100$ & $3,487,730,100$ & $4,020,750,000$ & $533,019,900$ & $\mathrm{NPV}$ & $631,745,317$ \\
\hline
\end{tabular}

Sumber : Olahan Data Primer, 2019.

Hasil analisis pada tabel 9 diperoleh nilai investasi agroindustri kopi bubuk organik selama 10 tahun adalah sebesar Rp 237.912.000. Biaya operasional selama 10 tahun adalah sebesar $\mathrm{Rp}$ 3.249.818.100 sehingga diperoleh biaya total sebesar Rp 3.487.730.100. Total penerimaan agroindustri kopi bubuk organik selama 10 tahun adalah sebesar Rp 4.020.750.000 sehingga diperoleh total pendapatan usaha selama 10 tahun adalah sebesar Rp. 533.019.900.

Dari perhitungan NPV selama 10 tahun usaha yaitu dari tahun 2009 sampai tahun 2019 dengan menggunakan Compounding Faktor tingkat suku bunga acuan sebesar 7\% maka diperoleh nilai NPV adalah sebesar Rp 631.745.317. Berdasarkan analisis diperoleh bahwa nilai NPV >0, Hal ini menunjukan bahwa agroindustri kopi bubuk organik di Desa Gunung Terang Kecamatan Way Tenong Kabupaten Lampung Barat layak secara financial.

\section{Analisa IRR (Internal Rate of Return)}

IRR menunjukkan kemampuan suatu investasi atau usaha dalam menghasilkan return atau tingkat keuntungan yang bisa dipakai. Kriteria yang dipakai untuk menunjukkan bahwa suatu usaha layak dijalankan adalah jika nilai IRR lebih besar dari tingkat suku bunga yang berlaku pada saat usaha tersebut diusahakan (Gittinger, 2009). Jadi, jika IRR lebih tinggi dari tingkat bunga bank atau lebih tinggi dari Social Oportunity Cost of Capital (SOCC) maka usaha yang direncanakan layak secara finansial untuk dilaksanakan. Jika IRR lebih kecil dari SOCC maka usaha yang direncanakan tidak layak secara finansial.

Tabel 10. Analisis IRR Agroindustri Kopi Bubuk Organik di Desa Gunung Terang Kecamatan Way Tenong Lampung Barat, Tahun 2009- 2019.

\begin{tabular}{rcccrcc}
\hline Tahun & Tahun Ke & Net Benefit & CF 7\% & Present Value 7\% & CF 33\% & Present Value 33\% \\
\hline 2009 & 10 & $(121,421,000)$ & 1.9672 & $(238,853,485)$ & 17.32 & $(4,136,642,521)$ \\
2010 & 9 & $39,110,000$ & 1.8385 & $71,902,140$ & 13.02 & $936,281,805$ \\
2011 & 8 & $39,430,000$ & 1.7182 & $67,748,081$ & 9.79 & $663,300,197$ \\
2012 & 7 & $60,935,000$ & 1.6058 & $97,848,294$ & 7.36 & $720,302,208$ \\
2013 & 6 & $60,035,000$ & 1.5007 & $90,096,347$ & 5.53 & $498,674,346$ \\
2014 & 5 & $50,635,000$ & 1.4026 & $71,018,207$ & 4.16 & $295,547,920$ \\
2015 & 4 & $78,709,000$ & 1.3108 & $103,171,443$ & 3.13 & $322,824,189$ \\
2016 & 3 & $99,684,000$ & 1.2250 & $122,117,186$ & 2.35 & $287,297,411$ \\
2017 & 2 & $86,520,700$ & 1.1449 & $99,057,549$ & 1.77 & $175,222,899$ \\
2018 & 1 & $117,962,200$ & 1.0700 & $126,219,554$ & 1.33 & $167,872,007$ \\
2019 & 0 & $21,420,000$ & 1.0000 & $21,420,000$ & 1.00 & $21,420,000$ \\
\hline & $533,019,900$ & NPV & $631,745,317$ & NPV & $(47,899,538)$ \\
\hline
\end{tabular}

$$
\begin{aligned}
\mathbb{R R} & =\quad \text { il }+\frac{\mathrm{NPV}+}{(\mathrm{NPV}+)-(\mathrm{NPV}-)} \times(\mathrm{i} 2-\mathrm{il}) \\
\mathbb{R} R & =7+\frac{631,745,317}{679,644,855} \times(33-7) \\
& =7+\frac{631,745,317}{679,644,855} \times(26) \\
& =7+0.929522694 \times(26) \\
& =7+24.16759005 \\
& =31.17
\end{aligned}
$$

Sumber : Olahan Data Primer, 2019.

Berdasarkan perhitungan pada tabel 10 diperoleh nilai NPV positif (+) adalah sebesar Rp 631.745.317 dan nilai NPV negatif (-) terkecil dengan nilai interest (i $\left.i_{2}\right)$ sebesar $33 \%$ adalah sebesar $\mathrm{Rp}$ (47.899.538). Berdasarkan hasil perhitungan dengan menggunakan Compounding Faktor, maka diperoleh nilai IRR agroindustri kopi bubuk organik adalah sebesar $31,17 \%$ yang artinya jika uang tersebut dikembangkan untuk usaha agroindustri kopi bubuk organik maka akan menghasilkan tingkat keuntungan sebesar $31,17 \%$ yang sudah didiskonto. Nilai IRR sebesar 31,17 \% lebih besar daripada nilai SOCC (Social Opportunity Cost of Capital) sebesar 7\%. Hal ini menunjukan bahwa agroindustri kopi bubuk organik di Desa Gunung Terang Kecamatan Way Tenong Kabupaten Lampung Barat layak secara financial.

\section{Analisa Net $\mathbf{B} / \mathbf{C}$}

Net Benefit Cost Ratio adalah penilaian yang dilakukan untuk melihat tingkat efisiensi penggunaan biaya berupa perbandingan jumlah nilai bersih sekarang yang positif dengan jumlah nilai bersih 
sekarang yang negatif, atau dengan kata lain Net B/C adalah perbandingan antara jumlah NPV positif dangan jumlah NPV negatif. Net B/C menunjukan nilai pendapatan bersih setelah dikenai bunga bank. Kriteria ini memberikan pedoman bahwa suatu proyek akan dipilih apabila nilai (Net $B / C>1$ ), sebaliknya bila suatu proyek memberikan nilai (Net $B / C<1)$, maka proyek tidak diterima (diteruskan).

Tabel 11. Analisa Net B/C Agroindustri Kopi Bubuk Organik di Desa Gunung Terang Kecamatan Way Tenong Lampung Barat, Tahun 20092019.

\begin{tabular}{rcrrr}
\hline Tahun & Tahun Ke & \multicolumn{1}{c}{ Net Benefit } & CF 7\% & Present Value 7\% \\
\hline 2009 & 10 & $(121,421,000)$ & 1.9672 & $(238,853,485)$ \\
2010 & 9 & $39,110,000$ & 1.8385 & $71,902,140$ \\
2011 & 8 & $39,430,000$ & 1.7182 & $67,748,081$ \\
2012 & 7 & $60,935,000$ & 1.6058 & $97,848,294$ \\
2013 & 6 & $60,035,000$ & 1.5007 & $90,096,347$ \\
2014 & 5 & $50,635,000$ & 1.4026 & $71,018,207$ \\
2015 & 4 & $78,709,000$ & 1.3108 & $103,171,443$ \\
2016 & 3 & $99,684,000$ & 1.2250 & $122,117,186$ \\
2017 & 2 & $86,520,700$ & 1.1449 & $99,057,549$ \\
2018 & 1 & $117,962,200$ & 1.0700 & $126,219,554$ \\
2019 & 0 & $21,420,000$ & 1.0000 & $21,420,000$ \\
\hline
\end{tabular}

$\begin{aligned} \text { Net } B / C & =\frac{\sum(\mathrm{NB}) \overline{(+)}}{\sum(\mathrm{NB}) \overline{(-)}} \\ & =\frac{870,598,802}{238,853,485} \\ & =3.64\end{aligned}$

Sumber : Olahan Data Primer, 2019.

Nilai net $\mathrm{B} / \mathrm{C}$ diperoleh dengan menjumlahkan nilai Present Value Benefit (PVB) positif (+) kemudian hasilnya dibagi nilai PVB negatif (-). Berdasarkan hasil perhitungan pada tabel 11, diperoleh nilai PVB positif adalah sebesar Rp 870.598.802. Nilai PVB negatif adalah sebesar $\mathrm{Rp}$ 23.8853.485 sehingga diperoleh nilai Net B/C adalah sebesar 3,64. Nilai net B/C 3,64 artinya bahwa setiap $\mathrm{Rp} 1$ modal yang dikeluarkan untuk agroindustri kopi bubuk organik maka akan diperoleh keuntungan bersih setelah didiskonto (dikenai suku bunga bank) sebesar Rp 3,64. Nilai Net $\mathrm{B} / \mathrm{C}>1$ berarti agroindustri kopi bubuk organik di Desa Gunung layak secara financial untuk dikembangkan. Berdasarkan perhitungan analiis NPV, IRR dan Net B/C menunjukan bahwa agroindustri kopi bubuk organik di Desa Gunung Terang Kecamatan Way Tenong Kabupaten Lampung Barat layak secara financial.

Tabel 12. Analisis Finansial Agroindustri Kopi Bubuk Organik di Desa Gunung Terang Kecamatan Way Tenong Lampung Barat, Tahun 20092019 pada Tingkat Suku Bunga 7\% (cf=7\%)

\begin{tabular}{clll}
\hline No & Uraian & Satuan & \multicolumn{1}{c}{ Nilai } \\
\hline 1. & NPV & Rp & 631.745 .317 \\
2. & IRR & $\%$ & 31,17 \\
3. & Net B/C & & 3,64 \\
\hline
\end{tabular}

Sumber : Olahan Data Primer, 2019.

\section{KESIMPULAN DAN SARAN}

\section{A. Kesimpulan}

Berdasarkan hasil penelitian ini, maka kesimpulan yang dapat dimbil adalah sebagai berikut :

1. Total biaya produksi agroindustri kopi bubuk organik di Desa Gunung Terang Kecamatan Way Tenong Kabupaten Lampung Barat dalam satu kali proses produksi adalah sebesar Rp 3.675.191, rata-rata penerimaan adalah sebesar $\mathrm{Rp}$ 4.550.000, pendapatan yang diterima adalah sebesar Rp 879.809. Nilai $\mathrm{R} / \mathrm{C}$ rasio adalah sebesar 1,24 menunjukan bahwa agroindustri kopi bubuk organik menguntungkan.

2. Besarnya nilai tambah agroindustri pengolahan kopi bubuk organik di Desa Gunung Terang Kecamatan Way Tenong Kabupaten Lampung Barat adalah sebesar Rp $27.459 / \mathrm{Kg}$. Hal ini menunjukan bahwa setiap penjualan $1 \mathrm{Kg}$ kopi bubuk organik maka akan memberikan nilai tambah sebesar Rp 27.459.

3. Agroindustri kopi bubuk organik di Desa Gunung Terang Kecamatan Way Tenong Kabupaten Lampung Barat layak (feasible) secara finansial untuk dikembangkan, hal ini dapat diketahui dari perhitungan nilai NPV yaitu sebesar Rp 631.745.317, nilai IRR adalah sebesar $31,17 \%$ dan nilai Net B/C sebesar 3,64.

\section{B. Saran}

Adapun saran yang dapat direkomendasikan berdasarkan hasil penelitian ini adalah sebagai berikut :

1. Hendaknya pengelola agroindustri kopi bubuk organik agar tetap memperhatikan dan menjaga kualitas produksi kopi bubuk organik yang dihasilkan dengan mempertahankan kopi bubuk organik yang memiliki citarasa yang khas.

2. Hendaknya pengelola agroindustri kopi bubuk organik agar dapat meningkatkan kapasitas produksi kopi bubuk organik yang dihasilkan serta dapat meningkatkan keahlian dan keterampilan pekerja.

3. Pemerintah melaui instansi terkait agar lebih memperhatikan dan membina agroindustri pengolahan kopi bubuk organik dengan mengikutserakan dalam kegiatan pameran maupun promosi usaha sehingga lebih dikenal masyarakat dan jangkauan pemasarannya menjadi lebih luas lagi

\section{DAFTAR PUSTAKA}

AAK. 2000. Budidaya Tanaman Kopi. Yayasan Kanisius: Yogyakarta.

Aulia, N. 2011. Pedoman Budidaya Tanaman Kopi. Tim Karya Tani Mandiri. Bandung.

Badan Pusat Statistik Propinsi Lampung. 2009. Lampung Barat Dalam Angka. 
Bandar Lampung Badan Pusat Statistik Provinsi Lampung. 2015. Lampung Dalam Angka 2015.Lampung.

Budhisatyarini, T. 2008. Nilai Tambah Diversifikasi Hasil Usahatani Bawang Merah Menjadi Bawang Goreng. Pusat Analisis Sosial Ekonomi dan Kebijakan Pertanian Departemen Pertanian. Bogor.

Direktorat Jenderal Perkebunan. 2016. Produksi Kopi Menurut Provinsi d Indonesia Tahun 2015. http: deptan.go.id/ infoeksekutif/bun/ BUN_asem2012/produksi_kopi [02 Maret 2019].

Gilarso. 2009. Teknologi Pengolahan Pangan Tradisional. CV. Bima Pustaka. Yogyakarta.

Haryono, Dwi. 2009. Dampak Industrialisasi Pertanian Terhadap Kinerja Ekonomi, Pendapatan Rumah Tangga dan Kemiskinan Pedesaan (Aplikasi Model Keseimbangan Ekonomi). Seminar Disertasi Fakultas Pertanian.

Heni P., T.F. Djaafar dan S. Rahayu. 2006. Diversifikasi Teknologi Pengolahan Jagung untuk Menunjang Agroindustri di Pedesaan. Prosiding Seminar Nasional. Universitas Muhammadiyah Yogyakarta.

Herman. 2008. Membangkitkan Kembali Peran Komoditas Kopi Bagi Perekonomian Indonesia. Diambil dari http://www. tumoutou.net/702_07134/herman.pdf pada tanggal 27 Februari 2019.

Ibrahim, Y. 2009. Studi Kelayakan Bisnis. Rineka Cipta. Jakarta.

Ipard. 2008. Kopi Organik. http://www.ipard.com. Diakses tanggal 18 Januari 2019.

Kartasapoetra, A.G. 2008. Pengantar Ekonomi Produksi Pertanian. Bumi Aksara. Jakarta.

Kementerian Perdagangan. 2018. Negara Tujuan 10 Komoditi Utama. http://www.kemendag.go.id. Diakses pada 27 Juni 2019.

Kotler, P. 2002. Manajemen Pemasaran. Perlindo. Jakarta.

Manulang. 2000. Analisis Harga. LP3ES. Jakarta.

Mubyarto. 2006. Pengantar Ekonomi Pertanian. LP3ES. Jakarta.

Mulyadi. 2007. Akuntansi Biaya. Edisi ke-5. Graha Ilmu. Yogyakarta.
Nazir, M. 2003. Metode Penelitian. Ghalia Indonesia. Jakarta.

Najiyati, S dan Danarti. 2016. Kopi Budidaya dan Penanganan Lepas Panen. Penebar Swadaya. Jakarta.

Nuraini, I. 2002. Pengantar Ekonomi Mikro. Universitas Muhammadiyah Malang, Malang.

Rahim, A. 2007. Ekonometrika Pertanian. LP3ES. Jakarta

Rahman, M. dan Ariani. 2002. Analisis Tingkat Ketahanan Pangan Rumah Tangga. Media Gizi dan Keluarga. 27 (2). 1-6.

Rukmana, R. 2007. Ubi Kayu Budidaya dan Pasca Panen. Kanisius. Yogyakarta.

Ricky, W. Ronal dan Ebert, J. 2006. Bisnis Akutansi Manajemen. Erlangga. Jakarta.

Sjarkowi, F dan Marwan, S. 2004. Manajemen Agribisnis. CV Baldad Grafiti Press. Palembang.

Sjarkowi, F. 2010. Manajemen Agribisnis. CV. Baldad Grafiti Press. Palembang.

Soekartawi. 2001. Analisis Usahatani. Universitas Indonesia. Jakarta

2002. Analisis Usahatani. Universitas Indonesia. Jakarta. - 2003. Pengantar Agroindustri. Raja Grafindo Persada. Jakarta.

Suratiyah, K. 2006. Ilmu Usahatani. Penebar Swadaya. Jakarta.

Syakir. 2010. Budidaya dan Panen Kopi. http://perkebunan.litbang.deptan.go.id/ wpcontent/upload/2012/08/perkebunan_budidaya_ kopi.pdf. (diakses pada 20 Februari 2019).

Umar, H. 2003. Studi Kelayakan Bisnis. PT. Raja Grafindo Persada. Jakarta.

Wargiono. 2009. Diversivikasi Tanaman Pangan. Alfabeta. Bandung.

Yudi. 2010. Sistem Agribisnis Terintegrasi Hulu Hilir. Muara Indah. Bandung. 